Aircraft Surveillance Systems

Radar Limitations and the Advent of the Automatic Dependent Surveillance Broadcast

Busyairah Syd Ali

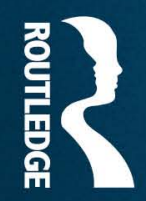




\section{Aircraft Surveillance Systems}

The Communication, Navigation and Surveillance (CNS) systems provide air traffic controllers with the information necessary to ensure the specified separation between aircraft and efficient management of airspace, as well as assistance to flight crew for safe navigation. However, the radar systems that support air traffic management (ATM), and in particular air traffic control (ATC), are at their operational limit. This is particularly acute in the provision of the ATC services in low altitude, remote and oceanic areas. Limitations in the current surveillance systems include unavailability of services in oceanic and remote areas, limited services during extreme weather conditions and outdated equipment with limited availability of spare parts to support system operation. These limitations have resulted in fatal accidents.

This book addresses the limitations of radar to support ATC in various operational environments, identified and verified by analysing five years of safety data from Avinor, the Air Navigation Service Provider (ANSP) in Norway. It derives a set of taxonomy and from this develops a causal model for incident/accident due to limitations in the surveillance system. The taxonomy provides a new method for ANSPs to categorize incidents while the causal model is useful for incident/ accident investigations. The book also provides theoretical justifications for the use of Automatic Dependent Surveillance Broadcast (ADS-B) to overcome the limitations of radar systems and identify areas of improvement to enable seamless ATC services.

Written in a style that makes it accessible to non-specialists, Aircraft Surveillance Systems will be of interest to many in the field of aviation, particularly ATM, safety and accident/incident investigation. It will also offer a useful reference on this vital topic for air traffic management courses. 
Dr Busyairah Syd Ali is Senior Lecturer at the Department of Software Engineering at University of Malaya, Malaysia. Strong passion and an interest in aviation led her to undertake a PhD in Air Traffic Management (ATM), which she completed at the Centre for Transport Studies, Imperial College London, United Kingdom. Dr Syd Ali has investigated the limitations of radar that lead to aircraft incidents, and has developed a safety assessment framework for a new surveillance technology called Automatic Dependent Surveillance Broadcast (ADS-B), and assessed its impact on air traffic management operations. She has outstanding expertise (15 years in aviation), gained through studies in Air Traffic Management as well as her work experience with the Department of Civil Aviation Malaysia and, throughout the course of her PhD, exposure to the operations of NATS UK, Avinor Norway, EUROCONTROL and easyJet. 


\section{Aircraft Surveillance Systems}

Radar Limitations and the Advent of the Automatic Dependent Surveillance Broadcast

\section{Busyairah Syd Ali}

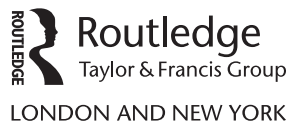


First published 2018

by Routledge

2 Park Square, Milton Park, Abingdon, Oxon OX14 4RN

and by Routledge

711 Third Avenue, New York, NY 10017

Routledge is an imprint of the Taylor \& Francis Group, an informa business

(C) 2018 Busyairah Syd Ali

The right of Busyairah Syd Ali to be identified as author of this work has been asserted by her in accordance with sections 77 and 78 of the Copyright, Designs and Patents Act 1988.

All rights reserved. No part of this book may be reprinted or reproduced or utilized in any form or by any electronic, mechanical, or other means, now known or hereafter invented, including photocopying and recording, or in any information storage or retrieval system, without permission in writing from the publishers.

Trademark notice: Product or corporate names may be trademarks or registered trademarks, and are used only for identification and explanation without intent to infringe.

British Library Cataloguing in Publication Data

A catalogue record for this book is available from the British Library

Library of Congress Cataloging in Publication Data

A catalog record for this book has been requested

ISBN: 978-1-4724-7797-2 (hbk)

ISBN: 978-1-315-56638-2 (ebk)

Typeset in Bembo

by Wearset Ltd, Boldon, Tyne and Wear 


\section{Contents}

List of figures vi vi

List of tables viii

List of abbreviations $\quad \mathrm{x}$

1 Communication, Navigation, Surveillance and Air Traffic Management 1

2 Air Traffic Control (ATC) surveillance environment 15

3 Radar system limitations $\quad 35$

4 Automatic Dependent Surveillance Broadcast (ADS-B) 60

5 Safety improvement potentials with ADS-B 100

6 ADS-B security 118

7 Conclusion 132

Bibliography 136

Index 143 


\section{Figures}

1.1 Paradigm shift in ATM technologies 3

1.2 CNS/ATM communication environment 7

1.3 A high-level view of benefits of the new CNS system to ATM

2.1 Generic ATC surveillance system 17

2.2 Primary Surveillance Radar 23

2.3 Secondary Surveillance Radar 24

3.1 Methodology to derive, validate and resolve limitations in the radar system 37

3.2 Methodology for derivation and validation of the new taxonomy

3.3 Improvement of ADREP and ESARR2 for an ATM specific occurrence category with the new taxonomy

3.4 Causal factor model for incidents/accidents due to limitations in the radar systems

3.5 Integrated Risk Picture (IRP) Risk Model 46

3.6 Radar locations for Norwegian airspace 50

3.7 Occurrence number and type for 2008-2012 52

3.8 Occurrence related to ATM supporting functions 53

4.1 Automatic Dependent Surveillance Broadcast (ADS-B) 61

4.2 ADS-B Out avionics 63

4.3 ADS-B In avionics 63

4.4 ADS-B Extended Squitter data format 74

4.5 High-level architecture of ADS-B 78

4.6 Context diagram for ADS-B data source, element $\begin{array}{ll}\text { and flow } & 80\end{array}$

4.7 ADS-B report generation process 81

4.8 Data flow between navigation source and ADS-B equipment 
Figures vii

4.9 Coded performance parameters for ADS-B 88

4.10 Air Traffic Management 94

4.11 New ATC system component 95

4.12 New ATC loop model 96

4.13 ATC functional blocks 98

$\begin{array}{lll}5.1 & \text { ADS-B system evolution } & 102\end{array}$

5.2 Manoeuvres supported by the Interval Management $\begin{array}{ll}\text { application } & 107\end{array}$

$\begin{array}{lll}5.3 & \text { Space-based ADS-B system } & 112\end{array}$

6.1 Destructive interference 126

$\begin{array}{ll}\text { 6.2 Constructive interference } & 127\end{array}$ 


\section{Tables}

2.1 Categories of existing surveillance technologies 18

2.2 Surveillance sensor performance characteristics 20

2.3 Surveillance application categories 21

2.4 Current and future separation management 34

3.1 Advantages and disadvantages of the current 39

3.2 New taxonomy validation by aviation experts from Avinor Norway

3.3 New causal model, IRP, CATS 48

3.4 IFR and VFR traffic for Norwegian airspace (2008-2012)

3.5 Incident, serious incident and accident for the year 2008-2012 (Norwegian airspace)

3.6 Categorization of causal factors for occurrence related to surveillance function

3.7 Questionnaire to Avinor

3.8 Mapping of causal factors (safety report) to derive causal factors

3.9 Example scenario (Avinor safety report) that shows correlation between system limitation and human error

3.10 Analysis of the Ueberlingen accident 58

4.1 Advantages and disadvantages of ADS-B system 64

4.2 ADS-B ground infrastructure components 66

4.3 ADS-B airborne infrastructure components 67

4.4 Aircraft equipage requirements for ADS-B Out and ADS-B In

4.5 GNSS RF carrier frequencies 70

4.6 Comparison between 1090ES, VDL4 and UAT 71 
4.7 1090ES ADS-B message, register and broadcast rates $\quad 75$

4.8 Message bits required for position encoding with and without CPR

4.9 ADS-B supported applications 82

4.10 ADS-B information required to support ADS-B applications

4.11 NIC values

4.12 NACp values

4.13 Summary of ADS-B surveillance performance requirements

4.14 Differences between DO-260, DO-260A and DO-260B

4.15 ATC paradigm shift based on phases of flight

5.1 Required information elements to support ADS-B applications

5.2 Minimum required ADS-B performance for airborne surveillance applications

5.3 Space-based ADS-B system specifications

5.4 A comparison of the ADS-B system and the radar system based on applications required by ICAO to accommodate increasing traffic

5.5 Potential mitigations for the limitations of the radar system 


\section{Abbreviations}

$\begin{array}{ll}\text { ADS } & \text { Automatic Dependent Surveillance } \\ \text { ADS-B } & \text { Automatic Dependent Surveillance Broadcast } \\ \text { AMSS } & \text { Aeronautical Mobile Satellite Service } \\ \text { ANSP } & \text { Air Navigation Service Provider } \\ \text { ASAS } & \text { Airborne Separation Assistance System } \\ \text { ASDE } & \text { Airport Surface Detection Equipment } \\ \text { ATC } & \text { Air Traffic Control } \\ \text { ATCo } & \text { Air Traffic Controller } \\ \text { ATM } & \text { Air Traffic Management } \\ \text { ATN } & \text { Aeronautical Telecommunication Network } \\ \text { ATS } & \text { Air Traffic Services } \\ \text { CAA } & \text { Civil Aviation Authority } \\ \text { CDTI } & \text { Cockpit Display of Traffic Information } \\ \text { CNS } & \text { Communication, Navigation and Surveillance } \\ \text { CNS/ATM Communication, Navigation, Surveillance and Air } \\ & \text { Traffic Management } \\ \text { DL } & \text { Data Link } \\ \text { DME } & \text { Distance Measuring Equipment } \\ \text { EEC } & \text { EUROCONTROL Experimental Centre } \\ \text { FAA } & \text { Federal Aviation Administration } \\ \text { FIR } & \text { Flight Information Region } \\ \text { FIS-B } & \text { Flight Information Service Broadcast } \\ \text { FMECA } & \text { Failure Mode Effects and Criticality Analysis } \\ \text { FOM } & \text { Figure of Merit } \\ \text { FSPN } & \text { Fluid Stochastic Petri Nets } \\ \text { FTA } & \text { Fault Tree Analysis } \\ \text { GBAS } & \text { Ground Based Augmentation System } \\ \text { GBT } & \text { Ground Based Transceiver } \\ \text { GNSS } & \text { Global Navigation Satellite System } \\ & \end{array}$




\begin{tabular}{|c|c|}
\hline GPS & Global Positioning System \\
\hline $\mathrm{HF}$ & High Frequency \\
\hline HFDL & High Frequency Data Link \\
\hline HFOM & Horizontal Figure of Merit \\
\hline HPL & Horizontal Protection Level \\
\hline IATA & International Air Transportation Association \\
\hline ICAO & International Civil Aviation Organization \\
\hline IFR & Instrument Flight Region \\
\hline ILS & Instrument Landing System \\
\hline INS & Inertial Navigation System \\
\hline IRS & Inertial Reference System \\
\hline ISO & International Organization for Standardization \\
\hline ITP & In-Trail Procedure \\
\hline MLAT & Multilateration System \\
\hline MSSR & Monopulse Secondary Surveillance Radar \\
\hline NAC & Navigational Accuracy Category \\
\hline NIC & Navigational Integrity Category \\
\hline NUC & Navigational Uncertainty Category \\
\hline OEM & Original Equipment Manufacturer \\
\hline OSI & Open System Interconnection \\
\hline PBN & Performance Based Navigation \\
\hline PSA & Probabilistic Safety Assessment \\
\hline PSR & Primary Surveillance Radar \\
\hline QoS & Quality of Services \\
\hline RAIM & Receiver Autonomous Integrity Monitoring \\
\hline RCP & Required Communication Performance \\
\hline RNAV & Area Navigation \\
\hline RNP & Required Navigation Performance \\
\hline RSP & Required Surveillance Performance \\
\hline RTCA & Radio Technical Committee for Aeronautics \\
\hline SADT & System Analyses and Design Technique \\
\hline SBAS & Satellite Based Augmentation System \\
\hline SIL & Source Integrity Level \\
\hline SIS & Signal In Space \\
\hline SL & Safety Level \\
\hline SMR & Surface Movement Radar \\
\hline SSR & Secondary Surveillance Radar \\
\hline TDOA & Time Difference of Arrival \\
\hline TIS-B & Traffic Information Service Broadcast \\
\hline TSO & Technical Standard Orders \\
\hline UAT & Universal Access Transceiver \\
\hline
\end{tabular}


xii Abbreviations

UAV Unmanned Aerial Vehicle

VDL VHF Data Link

VFR Visual Flight Region

VHF Very High Frequency

VOR VHF Omnidirectional Radio Range

WAAS Wide Area Augmentation System

WAM Wide Area Multilateration

WGS World Geodetic System 


\section{Communication, Navigation, Surveillance and Air Traffic Management (CNS/ATM)}

\subsection{Background}

Conventional air navigation systems such as radars, Instrument Landing System (ILS), VHF Omnidirectional Radio Range and Distance Measuring Equipment (VOR/DME), used for airspace surveillance, navigation and communication are ground-based systems. However, these systems suffer from a number of drawbacks including accuracy limits, range and line-of-sight limitations, being site-critical, the requirement for many installations and the considerable expense required for acquisition and maintenance. While significant advances have been made in hardware and software, the technology principle employed is typically more than 60 years old. Furthermore, these systems are unable to evolve to meet increasing traffic demands around airports, and are difficult to implement over large parts of the earth for example, because of remoteness and inhospitable terrain.

In 1983, the International Civil Aviation Organization (ICAO) gave the task of studying, identifying and assessing new concepts and technologies in the field of air navigation, including satellite technology, to a special committee. The Future Air Navigation Systems (FANS) Committee gathered together aviation specialists from around the world. In such a global forum, these specialists developed the blueprint for the system that would meet the needs of the aviation community well into the next millennium (ICAO, 1998a). The FANS concept, which came to be known as the Communication, Navigation, Surveillance and Air Traffic Management (CNS/ ATM) system, involves a complex and interrelated set of technologies, largely dependent on satellites, in order to overcome certain limitations of the existing systems. By adopting an approach whereby satellites would play a major role in communication, navigation and surveillance, the FANS Committee determined that states could 
substantially increase signal coverage over large parts of the earth with fewer infrastructures.

ICAO in 1992 endorsed CNS/ATM as the sole air navigation services (ANS) system for global application (ICAO, 1998b).

\subsection{Communication, Navigation, Surveillance and Air Traffic Management (CNS/ATM)}

ICAO defined CNS/ATM as "Communication, Navigation and Surveillance systems, employing digital technologies, including satellite systems together with various levels of automation, applied in support of a seamless global air traffic management system" (ICAO, 2000). The aim of CNS/ATM is to develop a comprehensive and unified system to support the provision of Air Traffic Services (ATS) to meet growth in air travel demand with associated improvements in safety, efficiency and regularity of air traffic, providing the desired routes to the airspace users, and homogenizing the use of equipment in different regions. CNS/ATM is underpinned by a high level of automation which reduces the dependency on the human and eliminates the current constraints to optimize the airspace. The distinct features of CNS/ATM are (ICAO, 2000):

- mix of satellite and ground-based systems - which enable internetworking for data transfer of communication, navigation and surveillance systems from technical sites to operational units to provide complete situational awareness to controllers and pilots;

- global coverage - which enables complete ATC services despite the geographical structure obstacles;

- seamlessness - whereby continuous and reliable services are available without fail to ensure safety;

- interoperable systems - whereby the system is designed as redundant architecture to provide uninterrupted services;

- use of air-ground data link - which enables synchronized situational awareness to controllers and pilots;

- use of digital technologies - to mitigate the limitations of analogue technologies such as noise interruption and to adapt to new digital application systems;

- various levels of automation - whereby more computer applications are used to aid controllers and pilots to perform the various job functions.

Figure 1.1 depicts the paradigm shift in ATM technologies, from the current CNS systems to the new CNS/ATM systems that are a mix of 


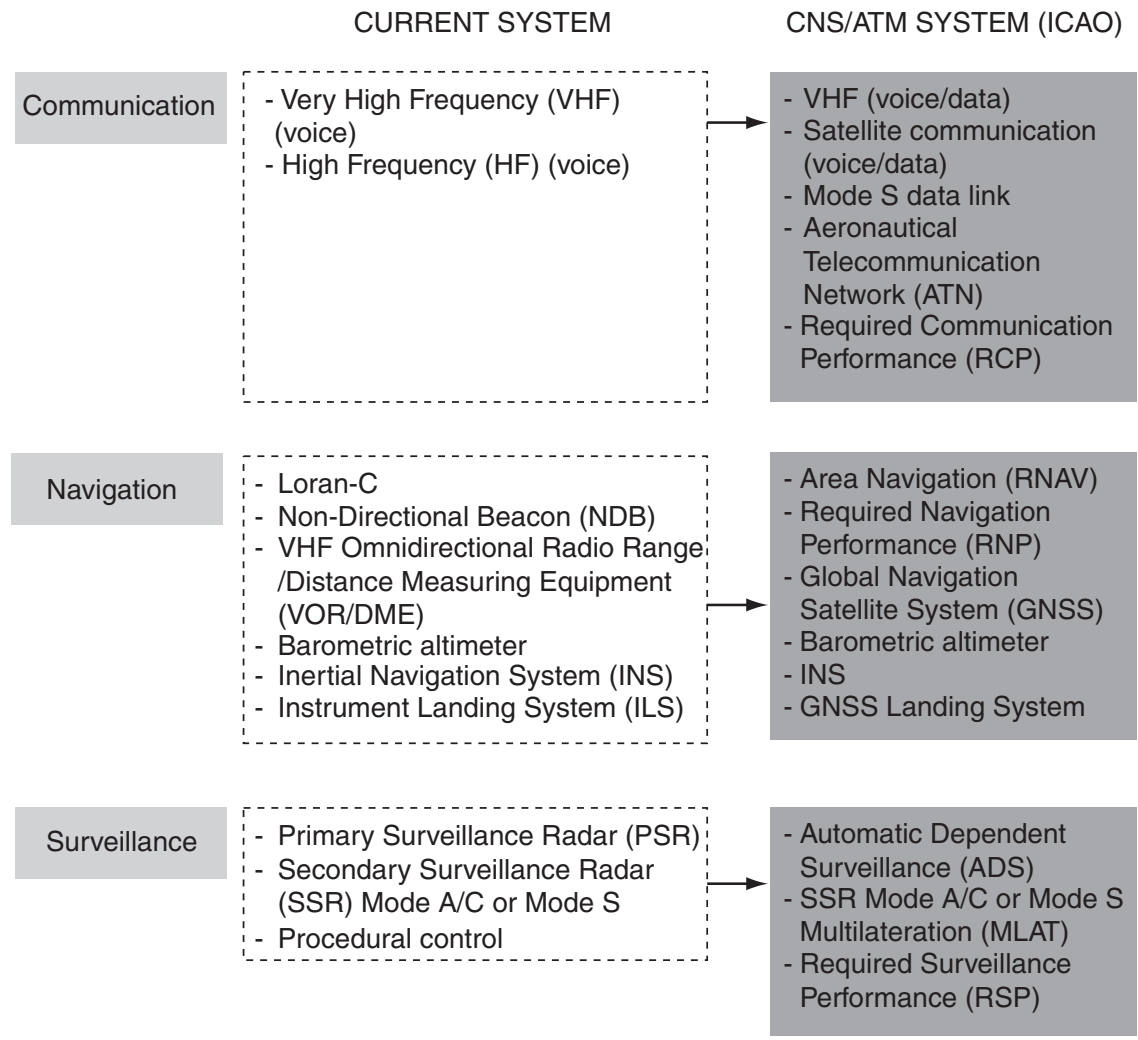

Figure 1.1 Paradigm shift in ATM technologies.

Source: modified from Vismari and Camargo, 2005.

satellite technology and the best of the line-of-sight systems. The new technologies have the potential to support advanced ATM applications such as Cockpit Display of Traffic Information (CDTI) (ICAO, 2003a) that provides situational awareness to pilots and In-Trail Procedure (ITP) (EUROCONTROL, 2009a) to give an aircraft more flexibility for efficient navigation especially in oceanic en-route areas. This in return benefits the airlines in terms of fuel consumption and most importantly reduces the environmental effects (Federal Aviation Administration, 2012). New supported applications are discussed in Chapter 4.

ICAO has developed a Global CNS/ATM Plan (ICAO, 2002a). Contracting states are to develop and implement a National CNS/ ATM Plan (ICAO, 2000) based on the ICAO Global Plan. For a 
period, current technology systems will co-exist with CNS/ATM systems until the transition to CNS/ATM is complete. The main elements of CNS/ATM are addressed in the following sections.

\subsubsection{Communication}

People and systems on the ground must communicate with the aircraft during all phases of flight. Good communications with timely and dependable availability are the cornerstone of operational safety and efficiency. Currently communication is primarily by means of voice. However, such analogue transmissions suffer from a number of shortcomings: they do not permit high rates of transmission of data and take up a great deal of valuable and diminishing frequency spectrum. This limits automation of routine functions and consequently the decisionmaking process for both the pilots and controllers.

In CNS/ATM systems, communications will increasingly be carried out using digital data links as these allow a high rate of data transfer, high reliability and integrity, improved frequency spectrum utilization and crucially, better interfacing with automated systems. There are two types of communication systems in place; air-ground communication and ground-ground communication. The current air-ground communication system relies on Very High Frequency (VHF), High Frequency (HF) and Ultra-High Frequency (UHF) analogue data links (radio frequency) for en-route and terminal areas, and Aeronautical Mobile Satellite Service (AMSS) for oceanic and remote continental airspace (ICAO, 2000), while the ground-ground communication relies on VHF data link. According to Hansman (1997), the current flight procedures and route structures have been developed and named based on the voice communication capabilities over low bandwidth VHF and HF links, resulting in limited coverage. Figure 1.1 shows the evolution of the communication technologies.

Future communication systems are based on digital data links such as High Frequency Data Link (HF DL), VHF Data Link Mode 4 (VDL-Mode 4), Mode S Extended Squitter and Universal Access Transceiver (UAT). Data link technologies enable uplink and downlink of four dimensional (4D) waypoints (latitude, longitude, altitude, time) and other data to pilots and controllers. Controller-Pilot Data Link Communication (CPDLC) is an example of a data link application that relies on HF DL, VDL and satellite communication 
(SATCOM). The implementation of the digital data links has the potential to change the communication of control instructions in the event of analogue voice link failure (Hansman, 1997).

Moreover, the analogue voice communication is prone to many limitations to the users, e.g. limited coverage, accessibility, capability, integrity and security. The voice communication performance, based on the radio frequency can reduce due to interference issues, frequency congestion and noise. This can happen, even though there are specific aviation frequency bands allocated for the ATC use. In addition, due to the different accents of the pilots and controllers, voice communication can lead to misinterpretation of information, which may cause undesired incidents. Despite its limitations, voice communication via radio frequency is still the main mode of communication between pilots and controllers in the ATC environment. Voice communication channels are regarded essential for ATC, since they act as a backup during the worst case (unavailability of surveillance and navigation functions) to enable continuous air traffic services to the users.

The implementation of enhanced modes of data link is envisioned to overcome the limitations discussed above. Therefore, the need for reliable digital data link technologies is crucial. However, the new digital communication technologies have to comply with the Required Communication Performance (RCP) (ICAO, 2006c) set by ICAO. The future communication systems in ATM are envisioned to be a mix of voice and data communication via high-speed digital data links.

\subsubsection{Aeronautical Telecommunication Network (ATN)}

The first step in implementing CNS/ATM, is the establishment of an efficient networking system for the communication of different forms of data, including text, radar, graphics and voice. This requires the use of a combination of terrestrial and satellite-based systems. The current system, the Aeronautical Fixed Telecommunication Network (AFTN), does not have the capability to support the future data requirements of CNS/ATM (ICAO, 2000). Therefore, ICAO proposes the use of the Aeronautical Telecommunication Network (ATN) that comprises application entities and communication services. These make the ground elements, air-ground networks and airborne data networks interact via the International Organization for Standardization (ISO) Open System Interconnection (OSI) reference model based protocol and services interface (ICAO, 1999a). ICAO has standardized the following data links in the context of ATN (ICAO, 1999c): 
- Aeronautical Mobile Satellite Service (AMSS), using satellites for communication, both geostationary and non-geostationary satellites, allowing communication by voice and data on a global range.

- VHF Data Link (VDL), using techniques of data communication in VHF bands. They are of types Mode 2, Mode 3 and Mode 4 with differentiation by their characteristics of modulation, control for access to the physical environment and, especially, data transfer rates.

- Mode S Extended Squitter (ES), operating on 1090/1030 MHz to communicate data in a bidirectional manner between air and ground elements with nominal rates of $4 \mathrm{Mbits} / \mathrm{s}$ (uplink) and $1 \mathrm{Mbits} / \mathrm{s}$ (downlink) (ICAO, 1998b).

- Universal Access Transceiver (UAT), a broadcast data link operating on $978 \mathrm{MHz}$, with a modulation rate of $1.041667 \mathrm{Mbps}$ (ICAO, 2009).

- HF Data Link (HFDL), which is the union between the characteristics of long-range electromagnetic propagation in the HF spectrum and digital data modulation, providing data communication in remote areas.

Vismari (2007) illustrates the CNS/ATM communication environment based on the ATN in Figure 1.2. ICAO categorized the application entities (AE), which are the functionalities of the ATN used by end systems (ES) in the air traffic system, into air-ground application entity and ground-ground application entity (ICAO, 1999a). The air-ground AE enables communication between ES on the ground (ATS units) and ES in the air (aircraft). Examples of applications in this category include:

- Automatic Dependent Surveillance Broadcast (ADS-B), which provides the aircraft position and other important information to the ES;

- Controller-Pilot Data Link Communication (CPDLC), which provides the ability to establish a peer-to-peer message communication between pilots and controllers;

- Flight Information Services (FIS), which allows pilots to request and receive flight information services; and

- Traffic Information Service Broadcast (TIS-B), which transmits radar surveillance information from the ground to the aircraft in the air.

The ground-ground AE allows communication between ES on the ground (ATS units). The AE in this category are the ATS Message 


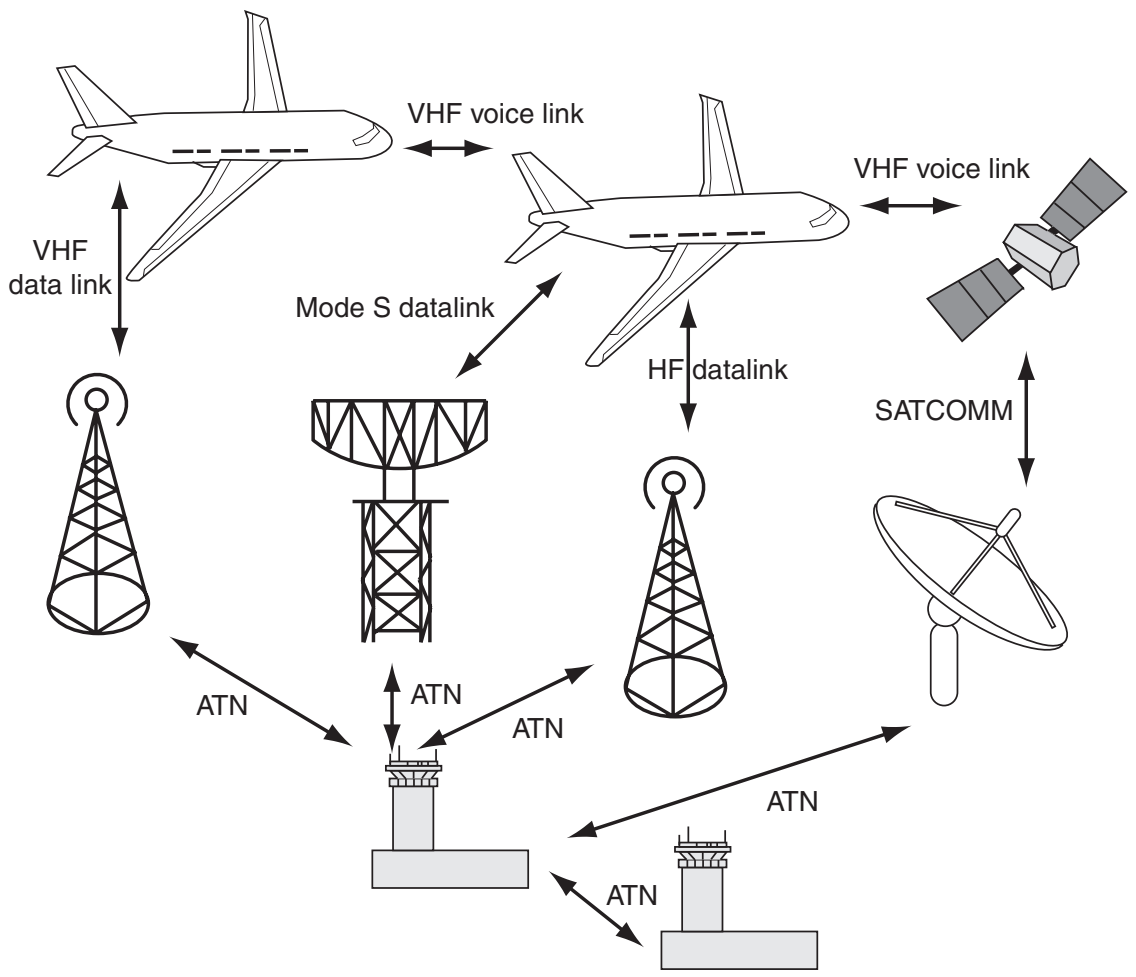

Figure 1.2 CNS/ATM communication environment.

Source: modified from Vismari, 2007.

Handling Service (ATSMHS), enabling the exchange of messages between ATS end users; and the Inter-Communication Centre (ICC), which provides message communication between ATS centres for notification, coordination and transfer of control activities.

An application developed based on the ATN is SESAR's and NextGen's System Wide Information Management (SWIM) (SESAR Joint Undertaking, 2011). SWIM is a holistic approach enabling information sharing including flight information, weather, aeronautical information and surveillance information among the stakeholders and the airspace users using a secure and flexible system (an intranet). SWIM infrastructure, over which the data are distributed, is interoperable (ground/ ground and air/ground). Its data communication link may differ from one user to another depending on available facilities. For SESAR's SWIM, the PAN European Network System (PENS) will provide the ground/ground data link. 


\subsubsection{Required Communication Performance (RCP)}

The communication function is one of the important elements of the ICAO's Future Air Navigation System - FANS concept (ICAO, 2007b). The Required Communication Performance (RCP) concept ensures that the communication system performance implemented within the ATM system is acceptably safe and reliable to operate in the ATM operational environment. It also includes the ATC ground equipment and aircraft equipage requirements for communication. The RCP concept is applicable to any communication capabilities to support the ATM functions despite technology type. Hence the concept can be applied to any new communication technology. The RCP concept assesses operational communication in the context of an ATM function, taking into account human interactions, procedures and environmental characteristics (ICAO, 2006c).

According to National Aeronautics and Space Administration (NASA), the concept enables diverse communication technologies to be measured in terms of communication process time (i.e. delay), integrity, availability and continuity of function (NASA, 2000). Therefore the concept provides means to quantify the communication system performance, essential to ensure the system safety. However, accuracy in predicting the process time can only be attained through monitoring during continuous operation. The accuracy parameter is not provided under the RCP concept.

\subsubsection{Navigation}

Navigation refers to the ability to determine the correct state of an object then to determine the course to steer and arrive at the next desired point (ICAO, 1998a).

The current ground-based navigation system consists of the use of VHF Omnidirectional Radio Range/Distance Measuring Equipment (VOR/DME), Non-Directional Beacon (NDB) and Long-Range Navigation (LORAN) for area navigation (RNAV) while Instrument Landing System (ILS) and Microwave Landing System (MLS) are used for precision approaches and landing (ICAO, 2000). In addition to these, ground navigation aids also include: Aeronautical Ground Lighting (AGL) system (e.g. status of runway, taxiway lighting panel), warning system (e.g. runway in use), internal lighting, meteorological equipment status, and alarming and reporting systems. Despite the system's good performance, a small number of significant deviations from 
cleared tracks still occur. These are mainly due to human error such as ATC loop errors (e.g. ATC issues incorrect clearance or flight crew misunderstands clearance message) or on-board navigation system errors (ICAO, 1990). On-board navigation systems include the Inertial Navigation System (INS) and the Global Positioning System (GPS) and its augmentations. These systems are described in detail in Chapter 4. The evolution of the current navigation systems is shown in Figure 1.1.

Improvements in navigation in CNS/ATM systems include the progressive use of Global Navigation Satellite Systems (GNSS), which provides world-wide coverage. It enables the aircraft to determine its own position on-board, from the information broadcast by the GNSS satellites. This advancement is envisaged to provide more flexibility to the pilot and to reduce the air traffic controller's workload. The availability of new GNSS constellations (e.g. Galileo) and the further development of augmentation means the Aircraft Based Augmentation System (ABAS), Ground Based Augmentation System (GBAS) and Satellite Based Augmentation System (SBAS) will improve the accuracy, availability and integrity of the navigation signal thus allowing enhanced positioning services in all phases of flight, including the airport surface (SESAR, 2008). For example, surface navigation based on GBAS (using enhanced positioning based on Galileo/GPS L5) should enable aircraft to navigate autonomously on the ground to the gate. The GNSS concept is explained further in Chapter 4.

\subsubsection{Required Navigation Performance (RNP)}

The need for the optimum utilization of airspace, which in turn depends on very high performance navigation systems, has resulted in the concept of Required Navigation Performance (RNP) by ICAO. The RNP is the navigation specification that includes a requirement for on-board navigation performance monitoring and alerting to enable an aircraft to fly a specific path between two three-dimensionally defined points in space. The RNP (ICAO, 1999b) concept applies to navigation performance within airspace; hence it covers both the airspace and aircraft that fly within it. The purpose of the RNP is to characterize airspace through the navigation performance accuracy value to be achieved within the airspace. Accuracy was the only parameter used to quantify the RNP characterization in the beginning.

According to ICAO, navigation performance accuracy is based on the combination of the navigation sensor error, airborne receiver error, 
display error and flight technical error (ICAO, 1999b). It refers to the level of accuracy required for a given block of airspace and/or a specific instrument procedure, e.g. a RNP of 10 means that a navigation system must be able to calculate its position to within a circle with a radius of 10 nautical miles. The level of RNP that an aircraft is capable of determines the separation required between it and other aircraft. Hence, the RNP values have to be more stringent for dense airspace, around noise sensitive areas or terrain areas compared to oceanic airspace.

The RTCA extended the RNP definition to include integrity, continuity and availability (RTCA, 1998). It was then known as Required Navigation Performance for Area Navigation (RNP-RNAV). The difference between RNP and area navigation (RNAV) is that the RNAV is a navigation specification that does not include a requirement for on-board navigation performance monitoring and alerting.

In order to implement a more practical navigation specification, ICAO developed Performance Based Navigation (PBN). PBN specifies that the aircraft RNP and RNAV system performance requirements are to be defined in terms of accuracy, integrity, continuity, availability and the functionalities required to operate in particular airspace supported by the appropriate navigation infrastructure (ICAO, 2008). The performance requirements are identified in the navigation specification, which also states the choice of navigation sensor and equipment that may be used to meet the performance requirements. PBN requirements depend on the ATC environment, communication, surveillance, navigational aids infrastructure, non-RNAV means of navigation available, functional and operational capabilities required to meet the Air Traffic Management application and the degree of redundancy required to ensure continuity of operations. The PBN provides specific implementation guidance in order to facilitate global harmonization. In this book, the term "RNP parameters" refers to accuracy, integrity, continuity and availability, which are defined in Chapter 4.

\subsubsection{Surveillance}

Surveillance, which refers to the methods used for keeping track of aircraft, is the third element of CNS/ATM. The surveillance function implementation includes sensors, display system and operational procedures, and provides air traffic controllers with the position of aircraft in order to perform separation management and to effectively manage 
a given airspace. Depending on the type of surveillance sensor, additional information such as aircraft identification and velocity is also presented. Furthermore, the surveillance function supports a number of other applications such as trajectory prediction, conflict detection and situational awareness.

Requirements for an Air Traffic Control (ATC) surveillance system depend on the applications. However, no single surveillance system is capable of meeting the surveillance requirements for all phases of flight in all types of airspace with traffic conditions that vary significantly from low to high-density traffic terminal areas. The current surveillance system in use consists of: Primary Surveillance Radar (PSR), Secondary Surveillance Radar (SSR), Monopulse Secondary Surveillance Radar (MSSR), Surface Movement Radar (SMR) and Multilateration (MLAT) systems. These technologies are explained in detail in Chapter 2. The evolution of the surveillance systems is illustrated in Figure 1.1. Recently a new surveillance technology, called Automatic Dependent Surveillance (ADS), has emerged, and is envisioned to support many new surveillance applications to meet future air traffic forecasts. ADS exploits the navigation and communication functions. The availability of different types of surveillance technologies provides flexibility to choose the most affordable and effective surveillance system suitable for the required operations, based on the operational environment. However, in order to maintain harmonization of the surveillance function, all the operational requirements have to be translated into a series of surveillance performance parameters irrespective of the surveillance technology.

\subsubsection{Required Surveillance Performance (RSP)}

The Required Surveillance Performance (RSP) is a set of well-quantified surveillance performance requirements such as capacity, availability, accuracy and update rate. Any single or combination of surveillance systems meeting the targets set for the parameters is considered operationally acceptable (ICAO, 2000). The only RSP document available to date is known as the Blue Book (EUROCONTROL, 1997), which is specifically meant for Primary Surveillance Radar (PSR) and classical Secondary Surveillance Radar (SSR Mode A/C). Therefore, it is not applicable to any new surveillance technology performance requirements. With the emergence of new surveillance technologies, all surveillance systems in the European Union are legally obliged to comply with the Single European Sky Essential Requirement (ER), which states: 
- Surveillance systems shall be designed, built, maintained and operated using appropriate and validated procedures in such a way as to provide the required performance applicable in a given environment (surface, TMA, en-route) with known traffic characteristics and exploited under an agreed and validated operational concept, in particular in terms of accuracy, coverage, range and quality of service.

- The surveillance network within the European Air Traffic Management Network (EATMN) shall be such as to meet the requirements of accuracy, timeliness, coverage and redundancy. The surveillance network shall enable surveillance data to be shared in order to enhance operations throughout the EATMN.

(EUROCONTROL, 2008)

This high-level requirement will be augmented by an Implementing Rule (IR), the Surveillance Performance and Interoperability Implementing Rule (SPI-IR) (EUROCONTROL, 2011a), which specifies how the essential rule is to be achieved. The SPI-IR is a legal requirement and includes regulations and general surveillance performance requirements (explained in Chapter 4). This implementing rule will remain in place until a generic global RSP is mandated by ICAO. This book adopts the surveillance performance requirements stipulated in this implementing rule.

\subsubsection{Air Traffic Management (ATM)}

Air Traffic Management (ATM) is a broadly defined function that includes air traffic services, air traffic flow management and airspace management. Its objective is to keep aircraft separated and enable aircraft operators to meet their planned times of arrival and departure while adhering to preferred flight (ICAO, 2002a). Integration of the new CNS technologies into the ATM will enable Air Traffic Services (ATS) providers to improve efficiency. By being better able to both accommodate an aircraft's preferred flight profile and reduce the minimum separation, aircraft operators and service providers could achieve reduced operating costs and minimize delays, while simultaneously freeing up additional airspace and increasing capacity. Figure 1.3 summarizes the benefits of the new CNS systems to the ATM. 


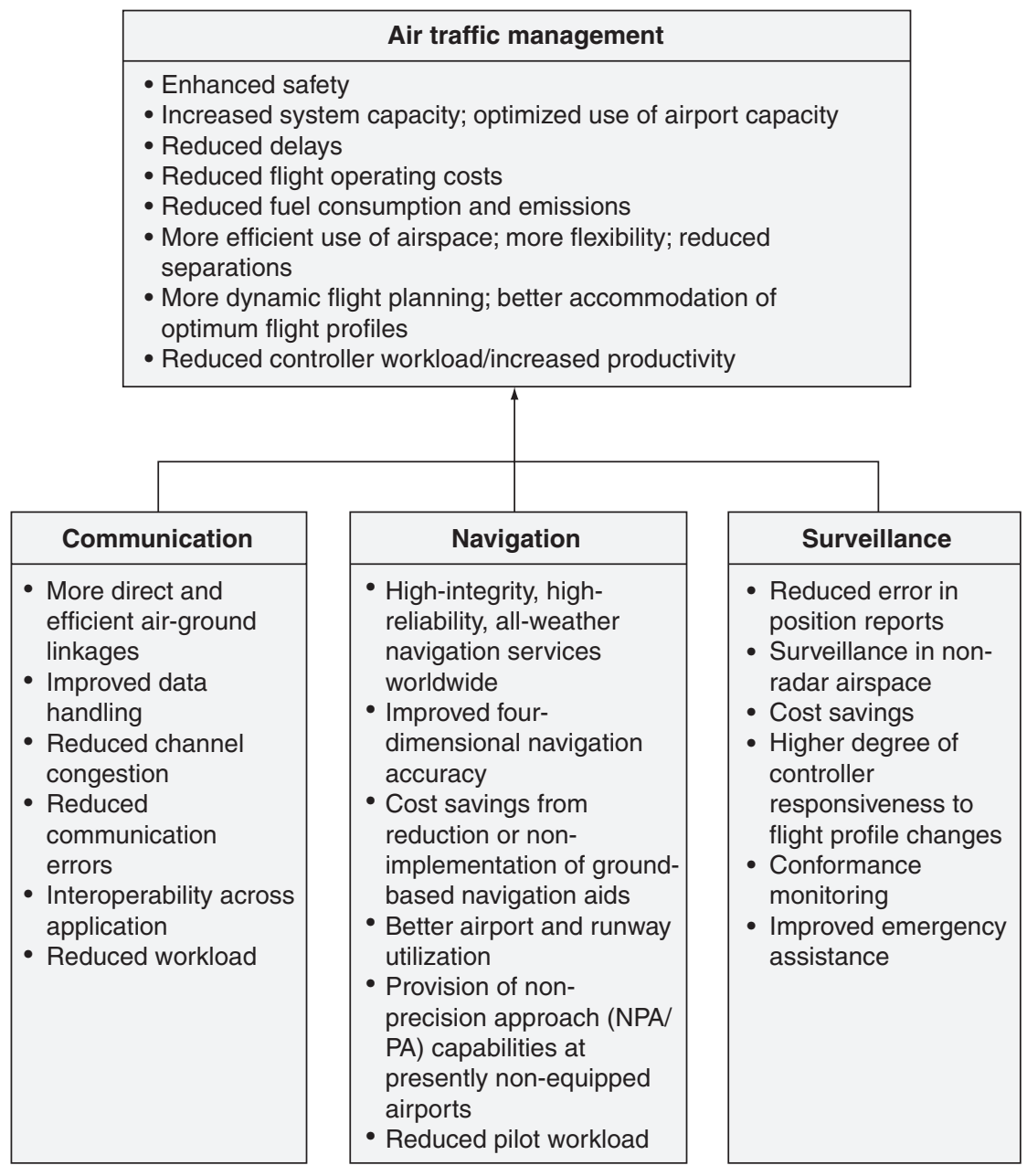

Figure 1.3 A high-level view of benefits of the new CNS system to ATM. Source: ICAO, 2002a.

\subsection{Impacts of evolution in CNS}

The paradigm shift in CNS, outlined in Figure 1.1, due to developments in technology, directly impacts the characteristics of ATM. Such impacts include the ATM system's ability to effectively manage the separation between aircraft due to: an increase in the accuracy, integrity and reliability of surveillance data, the larger coverage area, a reduction of congestion in the communication channels and the 


\section{References}

Adamy, D. L. 2001. EW 101: A First Course in Electronic Warfare. Boston, MA: Artech House. Aeronautical Surveillance Panel (ASP) 2007. Surveillance Manual. Draft 2.0 ed. ASP Working Group Meeting, Montreal.

Aireon 2016a. Space-Based ADS-B: Unlock Your ATM Potential. www.enav.it/enavWebPortalStatic/ATM2016/assets/aireon_brochuredef_1.pdf.

Aireon 2016b. Space Based ADS-B. In: International Civil Aviation Organization (ed.) TwentyFirst Meeting on the Improvement of Air Traffic Services over the South Atlantic (SAT/21). Lisbon, Portugal: ICAO.

Airports Authority of India 2014. Security Issues of ADS-B Operations. International Civil Aviation Organization, ADS-B Study and Implementation Task Force. Hong Kong, China. AirservicesAustralia 2007. ADS-B and TCAS.

Ale, B. 2009. Causal Model for Air Transport Safety. Delft: Risk Centre TU Delft.

Ali, B. S. 2016. System Specifications for Developing an Automatic Dependent SurveillanceBroadcast (ADS-B) Monitoring System. International Journal of Critical Infrastructure Protection, 15: 40-46.

Ali, B. S. , Majumdar, A. , Ochieng, W. Y., Schuster, W. and Chiew, T. K. 2015. A Causal Factors Analysis of Aircraft Incidents Due to Radar Limitations: The Norway Case Study. Journal of Air Transport Management, 44-45: 103-109.

Ali, B. S. , Ochieng, W. , Majumdar, A. , Schuster, W. and Chiew, T. K. 2014. ADS-B System Failure Modes and Models. The Journal of Navigation, 67: 995-1017.

Ali, B. S. , Schuster, W. and Ochieng, W. Y. 2016. Evaluation of the Capability of Automatic Dependent Surveillance Broadcast to Meet the Requirements of Future Airborne Surveillance Applications. The Journal of Navigation, 71: 49-66.

Avinor 2011. Avinor [Online]. Gardermoen, Norway Avinor AS. www.avinor.no/ [accessed 25 October 2011].

Barmore, B. , Penhallegon, W. J. , Weitz, L. A. , Bone, R. S. , Levitt, I. , Flores, J. A. , Kriegsfeld, D. A. and Johnson, W. C. 2016. Interval Management: Development and Implementation of an Airborne Spacing Concept. AIAA Guidance, Navigation, and Control Conference. San Diego, California, USA.

Bloem, E. A. , Blom, H. A. P. and Schaik, F. J. V. 2002. Advanced Data Fusion for Airport Surveillance. National Aerospace Laboratory.

Brooker, P. 2002. Future Air Traffic Management: Quantitative Enroute Safety Assessment: Part 1 - Review of Present Methods. The Journal of Navigation, 55: 197-211.

Brooker, P. 2004. Radar Inaccuracies and Mid-air Collision Risk: Part 2 - Enroute Radar Separation Minima. The Journal of Navigation, 57: 39-51.

Butterworth-Hayes, P. 2012. The Market for Wide-Angle/Beyond-Airport Surface ADS-B Surveillance. ATC Global Market Intelligence Reports.

Cascade Operational Focus Group 2008. Use of ADS-B for Enhanced Application of Own Visual Separation by Flight Crew on Approach (ATSA-VSA). EUROCONTROL.

Cascade Operational Focus Group 2009. Use of ADS-B for Enhanced Traffic Situational Awareness by Flight Crew During Flight Operations - Airborne Surveillance (ATSA-AIRB). EUROCONTROL.

Civil Air Navigation Service Organization 2014. Cyber Security and Risk Assessment Guide. CANSO.

Comsoft GmbH 2007. Automatic Dependent Surveillance - Broadcast (ADS-B) Deployment. www.airport-int.com/article/automatic-dependent-surveillance.html [accessed 2013].

Costin, A. and Francillon, A. 2012. Ghost Is in the Air (Traffic). Las Vegas, NV: Black Hat USA. Dawson, M. 2004. Understanding Mode S Technology. Aeroflex-Chandlers Ford UK.

De Oliveira, I. R. , Vismari, L. F., Cugnasca, P. S. , Camargo Junior, J. B. , Bakker, B. G. H. J. and Blom, H. A. P. 2009. A Case Study of Advanced Airborne Technology Impacting Air Traffic Management. In: L. Weigang , A. G. de Barros and I. R. de Oliveira (eds) Computational Models, Software Engineering and Advanced Technologies in Air Transportation: Next Generation Applications. Hershey, PA: IGI Global.

EASA 2008. Acceptable Means of Compliance for ADS-B Non-Radar Airspace. AMC 20-24. EUROCAE 2010. Technical Specification for Wide Area Multilateration (WAM) Systems. 101/ED-142. 
EUROCAE 2011. Safety Performance and Interoperability Requirements for Flight Deck Interval Management (ASPA-FIM). ED-195.

EUROCAE and RTCA 2010. Safety Performance and Interoperability Requirements for ATSAW during light operations (ATSAW-AIRB). ED-164/DO-319.

EUROCONTROL 1997. Eurocontrol Standard for Radar Surveillance in En-Route Airspace and Major Terminal Areas. EUROCONTROL.

EUROCONTROL 2001-2013. VHF Digital Mode 4. www.eurocontrol.int/services/vhf-digitalmode-4 [accessed 15 February 2013].

EUROCONTROL 2005. ATM Contribution to Aircraft Accidents/Incidents. Safety Regulation Commission Document.

EUROCONTROL 2006. Air Traffic Control (ATC).

www.eurocontrol.int/corporate/public/standard.page/cd-airtraffic_controller.html.

EUROCONTROL 2007. ADS-B for Dummies - 1090MHz Extended Squitter. EUROCONTROL.

EUROCONTROL 2008. The ATM Surveillance Strategy for ECAC. European Air Traffic

Management (EATM).

EUROCONTROL 2009a. CRISTAL-ITP Project. EUROCONTROL CASCADE Programme.

EUROCONTROL 2009b. Reporting and Assessment of Safety Occurrences in ATM. Safety

Regulatory Requirement, 3.0 ESARR2.

EUROCONTROL 2010. Annual Safety Report - 2010. EUROCONTROL.

EUROCONTROL 2011a. Surveillance Performance and Interoperability Implementing Rule (SPI-IR). Commission of the European Union. http://eur-lex.europa.eu/legal-

content/EN/ALL/;jsessionid=QcYRTxbZk87bQks5dZtTwvc5zSqF1gM1bvRN1CyQVpJ1tFFnrnfk! -2081994908?uri=CELEX:32011R1207 [accessed 13 April 2013].

EUROCONTROL 2011b. Transponder. https://extranet.eurocontrol.int/

http://atmlexicon.eurocontrol.int/en/index.php/Transponder\#Definition [accessed 1 November

2011].

EUROCONTROL 2016a. All-purpose Structured EUROCONTROL Surveillance Information

Exchange (ASTERIX). www.eurocontrol.int/services/asterix [accessed 30 August 2016].

EUROCONTROL 2016b. European ATM Master Plan. EUROCONTROL.

www.atmmasterplan.eu/data/projects/19074 [accessed 20 May 2016].

Federal Aviation Administration 2010a. Airworthiness Approval of Automatic Dependent

Surveillance - Broadcast (ADS-B) Out Systems. Advisory Circular AC 20-165.

Federal Aviation Administration 2010b. Automatic Dependent Surveillance Broadcast (ADS-B)

Out Performance Requirements to Support Air Traffic Control (ATC) Service. Final Rule, 14

CFR Part 91. Federal Registers 75 (103).

Federal Aviation Administration 2012. NextGen Implementation Plan. FAA.

German Federal Bureau of Aircraft Accidents Investigation 2004. Investigation Report.

Gibson, G. N. 2016. Constructive and Destructive Interference. High-Intensity Laser Physics. University of Connecticut.

Hansman, J. R. 1997. Integrated Human Centered System Approach to the Development of Advanced Cockpit and Air Traffic Management Systems. Air Traffic Management Research and Development Seminar, Sacley, France.

Herrera, I. A. , Nordskaga, A. O. , Myhreb, G. and Halvorsenb, K. 2009. Aviation Safety and Maintenance under Major Organizational Changes, Investigating Non-existing Accidents.

Accident Analysis \& Prevention, 41: 1155-1163.

Hollnagel, E. , Hoc, J. M. and Cacciabue, P. C. 1995. Work with Technology: Some Fundamental Issues. In: Expertise and Technology: Cognition and Human-Computer

Cooperation. New York: Lawrence Erlbaum Associates.

ICAO 1990. Automatic Dependent Surveillance. 226 AN/135.

ICAO 1993. Human Factors Digest no 7: Investigation of Human Factors in Accidents and Incidents. 240 AN/144.

ICAO 1998a. Address by the Director of the Air Navigation Bureau of the International Civil Aviation Organization (ICAO) - Mr. Jack Howell at the Official Opening of the World-wide CNS/ATM Systems Implementation Conference. Rio de Janeiro.

http://legacy.icao.int/icao/en/ro/rio/danb.htm [accessed 19 March 2010].

ICAO 1998b. Air Traffic Services Planning Manual. Montreal, Canada: International Civil

Aviation Organization (ICAO). 
ICAO 1998c. Manual on Airspace Planning Methodology for the Determination of Separation Minima. 9689 AN/953.

ICAO 1999a. Manual of Technical Provisions for the Aeronautical Telecommunication Network. 9705 AN/956.

ICAO 1999b. Manual on Required Navigation Performance (RNP). 9613 AN/937.

ICAO 1999c. Status of Air-Ground Data Link Standardization (Information Paper). 3rd Meeting of CAR/Sam (ICAO). Buenos Aires, Argentina.

ICAO 2000. National Plan for CNS/ATM Systems. 278 AN/164.

ICAO 2001. Aircraft Accident and Incident Investigation (Annex 13 to the Convention on International Civil Aviation).

ICAO 2002a. Global Air Navigation Plan for CNS/ATM Systems. 2nd ed. 9750 AN/963.

ICAO 2002b. ICAO Annex 10 Amendment 77 - Mode S Extended Squitter SARP.

ICAO 2003a. ADS-B Concept of Use (Working Paper 6 - Appendix). 11th Air Navigation Conference (ICAO). Montreal, Canada.

ICAO 2003b. Report of the Automatic Dependant Surveillance-Broadcast (ADS-B) Study and Implementation Task Force Meeting. Brisbane, Australia.

ICAO 2003c. Comparative Analysis of ADS-B Data Links (Information Paper 12). 11th Air Navigation Conference (ICAO). Montreal, Canada: International Civil Aviation Organization. ICAO 2004a. Advanced Surface Movement Guidance and Control Systems (A-SMGCS) Manual. 9830 AN/45.

ICAO 2004b. Manual of Secondary Surveillance Radar (SSR) Systems. 9684 AN/951.

ICAO 2004c. Manual on Mode S Specific Services. 9688 AN/952.

ICAO 2005. Global Air Traffic Management Operational Concept. 9854 AN/458.

ICAO 2006a. ADREP 2000 Taxonomy.

ICAO 2006b. Assessment of ADS-B to Support Air Traffic Services and Guidelines for Implementation.

ICAO 2006c. Manual on Required Communication Performance (RCP). 9869 AN/462.

ICAO 2006d. Procedures for Air Navigation Services - Aircraft Operations (PAN-OPS). 5th ed. 8168 OPS/611.

ICAO 2007a. Air Traffic Management (ATM). 15th ed. 4444 ATM/501.

ICAO 2007b. CNS/ATM Systems. www.icao.int/icao/en/ro/rio/execsum.pdf.

ICAO 2007c. Guidance Material on Comparison of Surveillance Technologies (GMST).

ICAO 2008. Performance Based Navigation (PBN) Manual. 9613 AN/937.

ICAO 2009. Manual on the Universal Access Transceiver (UAT).

ICAO 2010. Report of the 9th Meeting of ADS-B Study and Implementation Task Force. Jakarta, Indonesia.

ICAO 2012a. Difference between D0-260, D0-260A and D0-260B. ADS-B Study and Implementation Task Force.

ICAO 2012b. Manual on Airborne Surveillance Applications. 9994 AN/496.

ICAO 2012c. Report of the 12th Air Navigation Conference.

Institute of Air Navigation Services 2003. Automatic Dependent Surveillance. EUROCONTROL. Isaac, A. R. and Ruitenberg, B. 1999. Air Traffic Control: Human Performance Factors. Aldershot, Hants: Ashgate.

Joint Planning and Development Office (JPDO)-Air Navigation Services Working Group (ANSWG) 2008. FAA's Surveillance/Positioning Backup Strategy Alternatives Analysis. Next Generation Air Transportation System, Paper No.: 08-003.

Kunkel, R. 2009. Air Traffic Control: Insecurity and ADS-B. Defcon 17. Las Vegas, NV.

Lambert, M. , Riera, B. and Martel, G. 1999. Application of Functional Analysis Techniques to Supervisory Systems. Reliability Engineering and System Safety, 64: 209-224.

Lissandre, M. 1990. Maitriser SADT. Paris: Albert Colin.

McCallie, D. , Butts, J. and Mills, R. 2011. Security Analysis of the ADS-B Implementation in the Next Generation Air Transportation System. International Journal of Critical Infrastructure Protection, 4: 78-87.

Malaysian ICAO Annex 13 Safety Investigation Team for MH370 2016. 2nd Interim Statement. MH370 Safety Investigation. Kuala Lumpur, Malaysia: Ministry of Transport, Malaysia.

NASA 2000. Required Communication Performance (RCP).

http://as.nasa.gov/aatt/wspdfs/Oishi.pdf. 
NATS 2002. Evaluation of ADS-B at Heathrow for the EUROCONTROL ADS Programme Report.

NDTV 2010. A Phone Application That Threatens Security. Press Trust of India, 4 October. Olivier, B. , Gomord, P. , Honoré, N. , Ostorero, L. , Taupin, O. and Philippe, T. 2009. Multi Sensor Data Fusion Architectures for Air Traffic Control Applications. In: N. Milisavljevic (ed.) Sensor and Data Fusion. In-Tech.

Owusu, K. 2003. Draft Material for Manual on ATC Surveillance Architecture. Surveillance and Conflict Resolution System Panel (SCRSP) Working Group-B.

Perrin, E. and Kirwan, B. 2000. A Systemic Model of ATM Safety: The Integrated Risk Picture. EUROCONTROL ATM Seminar.

Rekkas, C. 2013. Progress of WAM, ADS-B Out and ATSAW deployment in Europe. In: German Institute of Navigation (ed.) International Symposium on Enhanced Solutions for Aircraft and Vehicle Surveillance Applications (ESAVS). Berlin, Germany.

Royal Academy of Engineering 2011. Global Navigation Space Systems: Reliance and Vulnerabilities. London: The Royal Academy of Engineering.

RTCA 1998. Minimum Aviation System Performance Standards for Required Navigation Performance for Area Navigation.

RTCA 2002. Minimum Aviation System Performance Standards for Automatic Dependant Surveillance Broadcast (ADS-B).

RTCA 2006a. Minimum Aviation System Performance Standards for Automatic Dependant Surveillance Broadcast (ADS-B).

RTCA 2006b. Minimum Operational Performance Standards (MOPS) for Traffic Alert and Collision Avoidance System II (TCAS 11) Hybrid Surveillance.

RTCA 2008. Safety, Performance and Interoperability Requirements Document for the In-Trail Procedure in Oceanic Airspace (ATSA-ITP) Application.

RTCA 2011a. Minimum Operational Performance Standards for $1090 \mathrm{MHz}$ Extended Squitter Automatic Dependent Surveillance - Broadcast (ADS-B) and Traffic Information Services Broadcast (TIS-B). DO-260B.

RTCA 2011b. Minimum Operational Performance Standards for $1090 \mathrm{MHz}$ Extended Squitter Automatic Dependent Surveillance - Broadcast (ADS-B) and Traffic Information Services (TISB) with Corrigendum 1.

Selex System Integration 2013. Transponder. Christian Wolff. www.radartutorial.eu/13.ssr/sr17.en.html [accessed 16 February 2013].

Sensis Corporation 2009. An Expanded Description of the CPR Algorithm. RTCA 1090WP30-12.

SESAR 2008. The ATM Deployment Sequence D4.

SESAR Joint Undertaking 2011. System Wide Information Management (SWIM).

EUROCONTROL and European Commission.

www.sesarju.eu/sites/default/files/documents/reports/factsheet-swim.pdf.

Skybrary 2011. Safety Nets. www.skybrary.aero/index.php/Safety_Nets [accessed 28 October 2011].

Smith, A. , Cassell, R. , Breen, T., Hulstrom, R. and Evers, C. 2006. Methods to Provide System-wide ADS-B Back-up, Validation and Security. 25th AIAA/IEEE Digital Avionics Systems Conference.

Sporty's Pilot Shop 2015. Which ADS-B Receiver Should I Buy?

http://ipadpilotnews.com/2015/10/ads-b-receiver-buy-2/ [accessed 30 August 2016].

Stolzer, A. J. , Halford, C. D. and Goglia, J. J. 2008. Safety Management Systems in Aviation.

Farnham, Surrey: Ashgate.

Strohmeier, M. , Vincent, L. and Ivan, M. 2015. On the Security of the Automatic Dependent Surveillance-Broadcast Protocol. IEEE Communications Surveys \& Tutorials, 17: 1066-1087. Surveillance and Conflict Resolution Systems Panel 2004a. Report on Required Surveillance Performance (RSP) for Airborne Surveillance. SCRSP/1-WP/30.

Surveillance and Conflict Resolution Systems Panel 2004b. Intercept Functionality. SCRSP/1WP/23.

US Air Force 2013. GPS Satellite Outage Information.

http://adn.agi.com/SatelliteOutageCalendar/SOFCalendar.aspx [accessed 17 November 2013]. Vidal, L. 2010. ADS-B IN-ATSAW (Airborne Traffic Situational Awareness). CAAC-Thales ADSB Flight Operation Seminar. Beijing, China. 
Vidal, L. 2012. Airborne Traffic Situational Awareness. ICAO ADS-B Study and Implementation Task Force. Jeju: Airbus.

Vismari, L. F. 2007. Vigilancia Dependente Automatica no Controle de Trafego Aereo: avaliacao de risco baseada em Redes de Petri Fuides e Estocasticas. Master's in Engineering Degree Dissertation, School of Engineering, Universaiti of Sao Paulo, Brazil.

Vismari, L. F. and Camargo Jr. J. B. 2005. Evaluation of the Impact of New Technologies on Aeronautical Safety: An Approach through Modelling, Simulation and Comparison with Legacy Systems. Journal of Brazilian Air Transportation Research Society, 1: 19-30.

Vismari, L. F. and Camargo Jr. J. B. 2008. An Absolute-Relative Risk Assessment Methodology Approach to Current Safety Critical Systems and Its application to the ADS-B Based Air Traffic Control System. Symposium of Reliable Distributed System. Naples, Italy.

Vismari, L. F. and Camargo Jr. J. B. 2011. A Safety Assessment Methodology Applied to CNS/ATM-based Air Traffic Control System. Reliability Engineering and System Safety, 96: 727-738.

Wassan, J. 1994. Avionics Systems: Operation and Maintenance. Englewood, CO: Jeppesen. Wilke, S. and Majumdar, A. 2012. Critical Factors Underlying Airport Surface Accidents and Incidents: A Holistic Taxonomy. Journal of Airport Management, 6: 170-190.

Wood, A. 2006. After ADS-B Launch, Security Concerns Raised. Aviation International News. Zwegers, D. 2010. Using ADS-B for Accident Investigation and Prevention. ISASI Forum, 43: $23-25$. 